\title{
PEMIJAHAN IKAN HIAS BOTIA (Chromobotia macracanthus Bleeker) SECARA BUATAN DENGAN INJEKSI HORMON HCG (HUMAN CHORIONIC GONADOTHROPIN) DAN LHRH-A (LUTEINIZING HORMONE RELEASING HORMONE ANALOG)
}

\section{The Artificially Spawning of Botia Fish (Chromobotia macracanthus Bleeker) with HCG (Human Chorionoc Gonadothropin) and LHRH-a (Luteinizing Hormone Releasing Hormone Analog) Injection}

\author{
Handian Febyadi Eka Putra ${ }^{1}$, Seto Sugianto Prabowo Rahardjo ${ }^{1}$ dan Asep Permana ${ }^{2}$ \\ ${ }^{1}$ Budidaya Perairan, Fakultas Perikanan dan Ilmu Kelautan, Universitas Brawijaya \\ ${ }^{2}$ Balai Riset Budidaya Ikan Hias (BRBIH) Depok, Jawa Barat \\ *handianbp14@student.ub.ac.id
}

\begin{abstract}
Abstrak
Ikan botia (Chromobotia macracanthus Bleeker) merupakan ikan hias asli perairan Indonesia yang tepatnya berasal dari Sumatera dan Kalimantan. Ikan ini menjadi primadona dalam komoditas ikan hias karena keunikannya mulai dari bentuk tubuh, warna sampai bentuk mulutnya. Ikan botia merajai pasar ekspor dunia khususnya negara-negara Eropa. Namun hal tersebut tidak sebanding dengan ketersediaan ikan endemik ini. Saat ini, ikan botia yang diekspor masih mengandalkan tangkapan di alam. Balai Riset Budidaya Ikan Hias (BRBIH) Depok, Jawa Barat merupakan yang pertama dan satu-satunya balai yang dapat memijahkan ikan hias botia secara buatan dengan bantuan injeksi hormon HCG (Human Chorionic Gonadothropin) dan LHRH-a berupa ovaprim dan telah diproduksi secara massal. Pemijahan ikan botia dilakukan secara buatan dengan stimulasi hormon sebelum ikan distriping. Hal ini berfungsi untuk mengoptimalkan pemijahan mulai dari kualitas telur, sperma sampai perkembangan embrio sehingga meningkatkan produksi benih. Hasil yang didapat adalah rata-rata fekunditas di atas 5.000 telur, derajat pembuahan di atas $80 \%$, derajat penetasan telur di atas $60 \%$ serta derajat kelulushidupan larva yang lebih dari 50\%.
\end{abstract}

Kata Kunci: Chromobotia macracanthus Bleeker, Pemijahan Buatan dan Pembenihan

\begin{abstract}
Botia fish (Chromobotia macracanthus Bleeker) is endemic from Indonesia especially from Sumatera and Kalimantan. Botia fish is popular because it unique body shape, colours and mouth shape. Botia fish has been top order of export market especially at European. However, it is not comparable with the availability. Now, Botia fish which export is still relied from natural catch. Balai Riset Budidaya Ikan Hias (BRBIH) Depok, Jawa Barat is the most one agency that can spawned Botia fish by artificially with hormone injection of HCG (Human Chorionic Gonadothropin) and LHRH-a (Luteinizing Hormone Releasing Hormone) that is Ovaprim and it has been produced a lot. The Botia fish artificially spawning can do with injection of hormone before striping. The function is to optimizing the spawning start from egg quality, sperm and embryo so can improve the production. The result from this research is fecundity average is above 5.000 egg, fertilization rate above $80 \%$, hatching rat above $60 \%$ and survival rate above $50 \%$.
\end{abstract}

Keyword: Chromobotia macracanthus Bleeker, Artificial Spawning and Breeding

\section{PENDAHULUAN}

Ikan botia merupakan ikan hias endemic asal Indonesia khususnya Sumatera dan Kalimantan yang memiliki keunggulan dibandingkan ikan lainnya seperti pola warna dan bentuk tubuhnya. Menurut Sudarto et al. (2008), ikan botia menjadi komoditas ekspor terbesar karena diminati oleh pasar luar negeri. Namun produksinya di Indonesia masih mengandalkan tangkapan di alam. Sementara jika dibiarkan maka akan menyebabkan terjadinya overfishing sehingga dapat mengancam ketersediaan ikan botia di Indonesia. 
Pemijahan ikan botia dilakukan sama halnya dengan memijahkan ikan secara buatan pada umumnya. Menurut Gusrina (2014), pembenihan ikan secara buatan (induce breeding) merupakan teknik pemijahan ikan yang terjadi dengan memberikan rangsangan hormon untuk mempercepat kematangan gonad serta proses ovulasinya dilakukan secara buatan yaitu dengan teknik stripping/pengurutan.

Balai Riset Budidaya Ikan Hias (BRBIH) Depok, Jawa Barat merupakan yang pertama dan satu-satunya balai yang dapat memijahkan ikan hias botia dan telah memproduksi secara massal tergantung dari permintaan. Hal yang mendasari keberhasilan pemijahan dan pembudidayaan ikan botia adalah memanipulasi keadaan wadah pemeliharaan dan pemijahan dengan keadaan yang sebenarnya di alam. Indukinduk yang didapat dari alam didomestikasikan dan diadaptasikan dalam wadah pemeliharaan dan diberi pakan cacing tanah, cacing darah selama hampir delapan bulan (Satyani et al., 2006).

Jika keadaan wadah pemeliharaan tidak sesuai dengan keadaan di alam, maka nilai mortalitas ikan botia akan meningkat. Oleh karena itu dilakukan penelitian ini untuk mengetahui aspek apa saja yang harus diperhatikan untuk memanipulasi lingkungan sehingga ikan botia dapat dipijahkan dan menghasilkan benih yang berkualitas.

\section{METODOLOGI}

\section{Waktu dan Tempat}

Penelitian ini dilakukan pada bulan Juli sampai dengan Agustus 2017 di Balai Riset Budidaya Ikan Hias (BRBIH) Depok, Jawa Barat.

\section{Materi Penelitian}

Peralatan Penelitian

Alat yang digunakan pada penelitian ini adalah baskom, centong, penggaris, handuk, kateter, timbangan digital, spuit, seser, corong, selang, Styrofoam, cawan petri dan mikroskop.
Bahan Penelitian

Bahan yang digunakan pada penelitian ini adalah phenoxy, hormo HCG, ovaprim, air mineral dan ikan botia.

\section{Metode Penelitian}

Metode pada penelitian ini adalah menggunakan teknik pemijahan ikan secara buatan yakni dengan bantuan manusia secara keseluruhan dan stimulasi hormon untuk merangsang kematangan gonad ikan serta mempercepat proses spermiasi dan ovulasi.

\section{Prosedur Kerja Pengadaan Induk}

Pada manajemen induk dilakukan pengadaan induk terlebih dahulu yang didapat dari tangkapan alam sebanyak 40 ekor. Kolam pemeliharaan menggunakan bak kanvas berukuran $3 \mathrm{~m}$ kedalaman 70 $\mathrm{cm}$.Sex ratio ikan botia yakni 1:2 yang berarti 1 ikan betina dapat dibuahi oleh 2 ikan jantan.

\section{Persiapan Wadah}

Akuarium ukuran 100x40 cm disiapkan sebagai wadah pemijahan ikan botia. Akuarium diisi air dan bagian luarnya ditutupi plastik hitam. Hal ini berguna agar ikan botia yang ditempatkan tidak stress. Persiapan wadah pemijahan dilakukan 2 minggu sebelum kegiatan pemijahan berlangsung.

Sementara wadah penetasan telur terbuat dari corong dan gabus yang dikombinasikan agar telur dapat terpelihara dengan pergerakan debit air seperti pada Gambar 1.

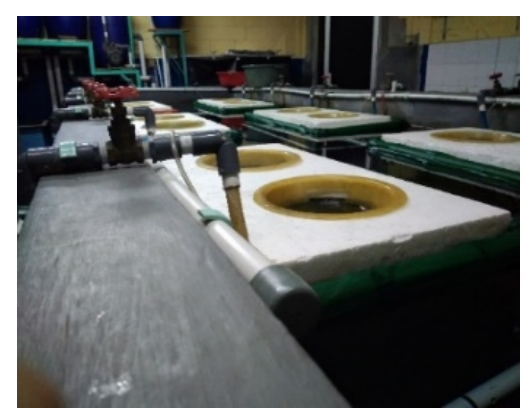

Gambar 1. Corong Penetasan Telur 


\section{Seleksi Induk}

Seleksi induk bertujuan untuk mengetahui induk ikan yang siap untuk memijah. Induk botia yang baik untuk dipijahkan adalah tidak cacat, berumur 1,5-2 tahun dan panjang total minimal 12$15 \mathrm{~cm}$. Perbedaan induk jantandan betina dapat dilihat pada Tabel 1.

Tabel 1. Perbedaan induk jantan dan betina

\begin{tabular}{|c|c|c|}
\hline No & Induk jantan & Induk betina \\
\hline 1. & $\begin{array}{l}\text { Ukuran tubuh } \\
\text { lebih kecil dan } \\
\text { ramping }\end{array}$ & $\begin{array}{l}\text { Ukuran tubuh } \\
\text { lebih besar }\end{array}$ \\
\hline 2. & $\begin{array}{l}\text { Bila distriping } \\
\text { mengeluarkan } \\
\text { sperma }\end{array}$ & $\begin{array}{l}\text { Bila distriping } \\
\text { mengeluarkan } \\
\text { telur }\end{array}$ \\
\hline 3. & Perut rata & $\begin{array}{l}\text { Perut } \\
\text { membuncit }\end{array}$ \\
\hline 4. & $\begin{array}{l}\text { Bobot berkisar } \\
22-174 \text { g/ekor }\end{array}$ & $\begin{array}{l}\text { Bobot berkisar } \\
46-251 \text { g/ekor }\end{array}$ \\
\hline
\end{tabular}

Induk yang telah siap memijah baik jantan maupun betina, pada bagian kelaminnya akan menonjol dan semakin lama akan semakin membesar hingga proses pemijahan ikan berlangsung. Pada jantan bentuk tonjolan akan menonjol sedangkan pada betina akan membulat dan memerah. Perbedaan induk jantan dan betina dapat dilihat pada Gambar 2 .

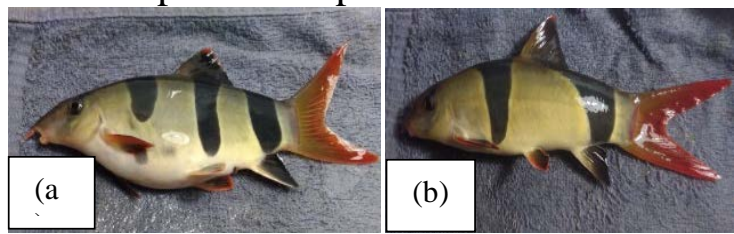

Gambar 2. (a) Induk Botia Jantan; (b) Induk Botia Betina

\section{Pemijahan}

Pemijahan secara buatan dengan stimulasi hormon yakni HCG (Human Chorionic Gonadothropin) dan LHRH-a (Luteinizing Hormone Releasing Hormone analog) berupa ovaprim. Sebelum proses pemijahan, induk terlebih dahulu melalui proses kanulasi yakni pengecekkan kelayakan telur yang sesuai kriteria. Pengecekkan dilakukan dengan menggunakan alat bantu kateter berupa selang kecil lentur yang dimasukkan ke dalam lubang urogenital lalu disedot dengan mulut sampai telur terbawa, setelah itu dilakukan pengecekkan diameter telur dan kriteria tertentu. Jika telur layak maka dapat dilakukan proses pemijahan. Induk diijeksikan hormon HCG pada pukul 00.00 WIB pada induk betina, pukul 15.00 WIB ovaprim pada induk jantan dan pukul 00.00 WIB ovaprim pada induk betina. Dosis penyuntikan hormon HCG yakni:

$$
H C G=\frac{0,3 x \text { Bobot tubuh ikan }}{1000}
$$

Sedangkan dosis penyuntikan ovaprim adalah:

$$
\text { Ovaprim }=\frac{0,6 \times \text { Bobot tubuh ikan }}{1000}
$$

Setelah diinjeksi hormon, ikan diinkubasi dalam wadah pemijahan dan selanjutnya dilakukan proses striping. Waktu laten ikan botia adalah 10-12 jam. Hormon yang digunakan dapat dilihat pada Gambar 3.

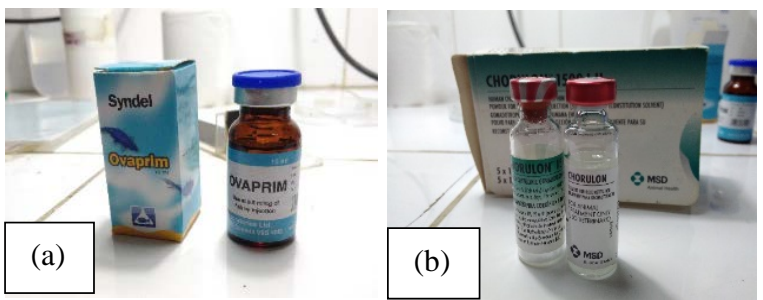

Gambar 3. Hormon

\section{Manajemen Pemeliharaan Larva Persiapan Akuarium Pendederan}

Persiapan akuarium untuk pendederan dan pemeliharaan larva yakni dengan menyiapkan akuarium berukuran 80x35x35 cm, kemudian akuarium yangtelah berisi air diberi kalium permanganate dan ditunggu selama 3 hariyang berfungsi untuk pengkondisian steril akuarium. Setelah itu membersihkan akuarium dengan menggunakan amplas halus yang digosokkan ke dinding dan dasar akuarium sambil disifon dan diisi air 
bersih diberi air setinggi $15 \mathrm{~cm}$ pada akuarium dan diberi aerasi secara terus menerus dan ditunggu hingga 2 minggu sebelum proses pendederan.

\section{Perhitungan Telur dan Pemanenan Larva}

Dalam proses penetasan telur hingga pemanenan larva ikan botia (C. macracanthus) terdapat beberapa proses yang harus dilakukan yaitu menghitung Fekunditas, derajat pembuahan (Fertilization Rate), derajat penetasan (Hatching Rate) dan tingkat kelangsungan hidup (Survival Rate).

- Fekunditas

Fekunditas merupakan jumlah total telur yang dihasilkan dalam satu kali pemijahan. Rumus menghitung fekunditas adalah:

$$
\text { Fekunditas }=\frac{\text { Bobot Total Telur }}{\text { Bobot } 1 \text { Telur }}
$$

- Derajat Pembuahan (FR)

Fertilization Rate merupakan derajat pembuahan yang dapat diperoleh mengetahui jumlah telur yang terbuahi pada satu siklus pemijahan dibagi dengan jumlah total telur. FR dapat dihitung dengan rumus:

$$
F R=\frac{\text { Jumlah Telur Terbuahi }}{\text { Jumlah Total Telur }} \times 100 \%
$$

- Derajat Penetasan (HR)

Hatching Rate merupakan persentase telur yang menetas pada proses pemijahan ikan dalam satu siklus. HR dapat dihitung dengan rumus:

$H R=\frac{\text { Jumlah Telur Menetas }}{\text { Jumlah Telur Terbuahi }} \times 100 \%$

- Tingkat Kelulushidupan (SR)

Survival Rate merupakan persentase tingkat kelangsungan hidup larva yang telah dipelihara selama proses inkubasi. SR dapat dihitung dengan rumus:

$$
S R \%=\frac{\text { Jumlah Larva Akhir }}{\text { Jumlah Larva Awal }} \times 100 \%
$$

\section{Pengepakkan dan Transportasi Benih}

Proses pengepakan ikan botia ( $C$. macracanthus) dilakukan dengan menggunakan plastik PX (Oxygen saving) dengan ukuran 60x30 cm. Ikan botia terlebih dahulu disortir untuk memisahkan antar ukuran yang berbeda dan jumlah yang disesuaikan. Pengepakan dilakukan dengan membuat plastik secara double dan diikat dengan karet gelang. Hal ini bertujuan agar tahan lama dan tidak mudah bocor. Setelah itu memberi air tawar sebanyak $1 / 3$ bagian dari plastik kemudian masukkan ikan yang sudah disortir berdasarkan ukuran dan jumlah yang dipesan. Selanjutnya keluarkan udara dalam plastik terlebih dahulu lalu beri oksigen dalam plastik dan selanjutnya diikat menggunakan 3 buah karet gelang agar tidak mudah lepas. Ukuran dan umur ikan botia dapat dilihat pada Tabel 2 .

Tabel 2. Ukuran dan Umur Ikan Botia

\begin{tabular}{cccc}
\hline No & Ukuran & $\begin{array}{c}\text { Umur } \\
\text { (bulan) }\end{array}$ & $\begin{array}{c}\text { Ukuran } \\
\text { (cm) }\end{array}$ \\
\hline 1 & S & 1 & $1-3$ \\
\hline 2 & $\mathrm{M}$ & 1,5 & $3-5$ \\
\hline 3 & $\mathrm{~L}$ & 2 & $5-7$ \\
\hline
\end{tabular}

Transportasi pengiriman ikan botia biasanya menggunakan kendaraan roda empat dan juga roda dua. Ikan yang sudah dipacking ditempatkan pada kendaraan dan langsung dilakukan pengiriman.

\section{HASIL DAN PEMBAHASAN}

Setelah telur berhasil distriping, maka dilakukan sampling berat telur menggunakan timbangan analitik untuk selanjutnya dapat menghitung nilai fekunditas masing-masing induk. Telur kemudian dicampur dengan sperma secara 
menyeluruh dan dibilas dengan air mineral hingga bersih. Hal ini bertujuan agar terjadinya fertilisasi sehingga telur-telur bisa langsugn diinkubasikan. Pembilasan dilakukan sebanyak tiga kali agar telur bersih menyeluruh. Penebaran telur dilakukan pada corong penetasan dengan air mengalir agar telur dapat terus bergerak. Selanjutnya yakni menghitung persentasi derajat pembuahan, derajat penetasan serta derajat kelulushidupan.

\section{Fekunditas}

Fekunditas keempat induk ikan botia pada saat pemijahan yakni berturuturut 18.345 butir, 18.654 butir, 13.634 butir dan 5.279 butir dengan bobot total telur 0,9 g dan bobot masing-masing telur yakni 0,10 g, 0,12 g, 0,10 g dan 0,10 g. Menurut Satyani et al. (2016), fekunditas ikan botia yang baik berkisar antara 3.000 sampai 20.000 butir telur untuk bobot tubuh 70-150 g.

\section{Derajat Pembuahan (FR)}

Persentase derajat pembuahan induk ikan botia yang dipijahkan berturuturut $81,6 \%$, 95,6\%, 57,3\% dan 93,6\% dengan jumlah telur sampling yang dihasilkan berkisar antara 142 sampai 352 butir dan jumlah telur yang terbuahi berkisar antara 116 sampai 207 butir. Hasil tersebut merupakan optimal karena persentase derajat pembuahan terbilang besar. Menurut Effendi et al. (2003), pembuahan telur oleh sel sperma berlangsung optimal ketika posisi inti telur berada di pinggir. Pembuahan sendiri merupakan peleburan inti sel telur oleh sel sperma, dengan beradanya inti sel telur di pinggir maka akan memudahkan sel sperma melakukan pembuahan.

\section{Derajat Penetasan (HR)}

Nilai persentase derajat penetasan induk ikan botia yang dipijahkan berturuturut adalah 63,7\%, 90,8\%, 44,8\% dan $57,9 \%$ dengan telur yang menetas berturuturut sebanyak 74 butir, 158 butir, 89 butir dan 120 butir. Hasil ini terbilang optimal karena derajat penetasan yang rendah yakni jika persentasenya tidak lebih dari 45\% (Satyani et al., 2010).

\section{Tingkat Kelulushidupan (SR)}

Persentase derajat kelulushidupan yang dihasilkan berturut-urut adalah $58,1 \%$, 57,8\%, 68,5\% dan 67,0\% dengan jumlah larva yang tersisa di akhir pemeliharaan yakni berkisar 387 sampai 3.175 ekor. Hasil ini terbilang optimal karena persentase kelulushidupan mencapai lebih dari 50\%. Menurut Satyani et al. (2016), nilai tingkat kelulushidupan yang baik yakni berkisar antara 50-70\%. Data pemijahan secara lengkap dapat dilihat pada Tabel 3.

Tabel 3. Data Pemijahan Ikan Botia

\begin{tabular}{ccccccccccc}
\hline No & $\begin{array}{c}\text { Bobot } \\
\text { Induk } \\
\text { Betina }\end{array}$ & Fekunditas & $\begin{array}{c}\text { Bobot } \\
\text { Telur } \\
\text { Sampel }\end{array}$ & $\begin{array}{c}\Sigma \text { Telur } \\
\text { dihasil- } \\
\text { kan }\end{array}$ & $\begin{array}{c}\Sigma \text { Telur } \\
\text { dibuahi }\end{array}$ & $\begin{array}{c}\text { FR } \\
(\%)\end{array}$ & $\begin{array}{c}\Sigma \text { Telur } \\
\text { Menetas }\end{array}$ & $\begin{array}{c}\text { HR } \\
(\%)\end{array}$ & $\begin{array}{c}\Sigma \\
\text { Larva }\end{array}$ & $\begin{array}{c}\text { SR } \\
(\%)\end{array}$ \\
\hline 1 & 237,9 & 18.345 & 0,10 & 142 & 116 & 81,6 & 74 & 63,7 & 2.625 & 58.1 \\
\hline 2 & 88,5 & 18.654 & 0,12 & 182 & 174 & 95,6 & 158 & 90,8 & 3.175 & 57,8 \\
\hline 3 & 76,5 & 13.634 & 0,10 & 352 & 202 & 57,3 & 89 & 44,0 & 976 & 68,5 \\
\hline 4 & 34,6 & 5.279 & 0,10 & 221 & 207 & 93,6 & 120 & 57,9 & 387 & 67,0 \\
\hline
\end{tabular}

\section{KESIMPULAN DAN SARAN Kesimpulan}

Pemijahan secara buatan dengan bantuan hormon HCG (Human Chorionic Gonadothropin) dan LHRH-a (luteinizing
Hormone Releasing Hormone analog) berupa ovaprim terbukti dapat mengoptimalkan pemijahan mulai dari aspek fekunditas yang berkisar antara 5.279 - 18.654 butir telur, derajat 
pembuahan antara 57,3\% - 93,6\%, derajat penetasan antara 57,9\% - 90,8\% serta tingkat kelulushidupan yang berkisar antara 57,8\% - 68,5\%.

\section{Saran}

Dalam kegiatan pemijahan ikan botia secara buatan terdapat beberapa aspek yang harus diperhatikan, diantaranya menjaga kebersihan alat yaitu dengan menyediakan biosecurity yang mumpuni sehingga meminimalisir adanya kontaminasi yang dapat menyebabkan kegagalan pada proses pemijahan.

\section{DAFTAR PUSTAKA}

Effendi, I., T. Prasetya., A. O. Sudrajat., N. Suhenda dan K. Sumawidjaja. 2003. Pematangan gonad induk ikan botia (Botia macracanthus) dalam kolam. Jurnal Akuakultur Indonesia 2(2) : 51-54.

Gusrina. 2014. Genetika dan Reproduksi Ikan. Dipublish Publisher. Yogyakarta.

Satyani, D., J. Slembrouck., S. Subandiyah dan M. Legendre. 2006. Peningkatan Teknis Pembenihan Buatan Ikan Hias Botia Chromobotia macracanthus (Bleeker). Jurnal Riset Akuakultur. 2(2) : 135-142.

Satyani, D., N. Meilisza dan L. Solichah. 2010. Gambaran pertumbuhan panjang benih ikan botia (Chromobotia macracanthus) hasil budidaya pada pemeliharaan dalam system hapa dengan padat penebaran 5 ekor per liter. Prosiding Forum Inovasi Teknologi Akuakultur 2010 : 395-402.

Satyani, D., J. Slembrouck., S. Subandiyah dan M. Legendre. 2016. Peningkatan teknis pembenihan ikan hias botia, Chromobotia macracanthus (Bleeker). J. Ris. Akuakultur 2 (2) : 135-142.

Sudarto., L. Pouyaud dan R. B. Kusuma. 2008. Struktur Populasi Dan Sejarah Kolonisasi Ikan Botia
(Chromobotia Macracanthus)

Kalimantan Berdasarkan Sekuen Intron Dari Gen Aldolase-B. Jurnal Perikanan. 10(2) : 203-212. 